\title{
Assessment of ecological risk and identification sources of polycyclic aromatic hydrocarbons at coastal sediments: A case study in Bushehr Province, Iran
}

\author{
Ghafour Nourian $^{1}{ }^{\circledR}$, Neamat Jaafarzadeh Haghighi Fard ${ }^{2,3^{*}}{ }^{(}$, Abdul Rahim Pazira $^{1}$, Esmaeil Kohgardi $^{1}$ \\ ${ }^{1}$ Department of Environment, Bushehr Branch, Islamic Azad University, Bushehr, Iran \\ ${ }^{2}$ Invited advisor, Department of Environment, Bushehr Branch, Islamic Azad University, Bushehr, Iran \\ ${ }^{3}$ Environmental Technologies Research Center, Ahvaz Jundishapur University of Medical Sciences, Ahvaz, Iran
}

\begin{abstract}
Background: Polycyclic aromatic hydrocarbons (PAHs) are stable and highly toxic environmental pollutants, which are produced mainly through combustion processes. The present study aimed to identify and determine PAHs compounds and their ecotoxicological effects in surface sediments of 20 stations in Bushehr province (Assaluyeh, Kangan, Khark, Emam Hasan, and Bushehr areas).

Methods: All sediment samples $(0-5 \mathrm{~cm})$ were collected from 20 sites of Persian Gulf costs (Bushehr province, Iran). The concentration of PAHs was determined by HPLC. Then, in order to identify the sources of PAHs, $\Sigma \mathrm{LPAHs} / \Sigma \mathrm{HPAHs}, \mathrm{IP} /(\mathrm{IP}+\mathrm{BP}), \mathrm{PH} / \mathrm{AN}$, and $\mathrm{AN} /(\mathrm{PH}+\mathrm{AN})$ ratios were obtained. Sediment quality guidelines (SQGs) and sediment quality criteria (SQC) were used to measure the PAHs ecotoxicological effects in sediments.

Results: Based on PAHs isomeric ratios, the contaminants of sediments originated from pyrogenic resources. $\Sigma$ PAHs values (ng/g dw) in sediment samples ranged from ND to 49180 . The toxic equivalent concentration (TEQ car) of PAHs raged from ND-7999 ngTEQ/g. Based on SQGs and SQC, the concentrations of $\Sigma \mathrm{PAHs}$ compounds in $10 \%$ and $6 \%$ of the sampling stations exceeded effects range median (ERM) and frequent effect level (FEL), respectively, indicating negative ecological risk effects. Conclusion: Sampling stations sediments must be routinely checked for PAHs because may lead to a negative effect on the marine ecosystem, organisms, and humans.

Keywords: Polycyclic aromatic hydrocarbons, Ecosystem, Environmental pollutants, Chromatography, Ecotoxicology, Geologic sediments

Citation: Nourian G, Jaafarzadeh Haghighi Fard N, Pazira AR, Kohgardi E. Assessment of ecological risk and identification sources of polycyclic aromatic hydrocarbons at coastal sediments: A case study in Bushehr Province, Iran. Environmental Health Engineering and Management Journal 2021; 8(4): 257266. doi: 10.34172/EHEM.2021.29.
\end{abstract}

Article History:

Received: 21 March 2021 Accepted: 14 June 2021 ePublished: 25 October 2021

\section{Introduction}

Polycyclic aromatic hydrocarbons (PAHs) are one of the main contaminants produced using defective ignition of organic compositions at pyrolysis (1-7). The PAHs generic structure is made of two and more aromatic rings in form of lineal, racemose, and angular (8). PAHs are mainly hydrophobic and organic lipophilic compounds, which are composed of hydrogen and carbon (9-11). PAHs composed of four or more aromatic rings are considered as heavy PAHs (HPAHs), whereas compounds with less than four rings comprise light PAHs (LPAHs) $(12,13)$. Exposure to PAHs causes adverse safety effects, including carcinogenic, reproductive defects, bioaccumulation, and mutagenic for humans and other organisms (14-17). PAHs can be formed in three ways: Pyrogenic, petrogenic, and biological $(10,18-20)$. The persistent sources of PAHs in the environment are anthropogenic, such as ship transit, municipal runoff, petroleum leakage, water, and industrial sewage, which leads to the entry of PAHs into aquatic environments $(2,21,22)$.

In aquaticenvironments, PAHsareplaced on sedimentary material and may decrease their bioavailability and biodegradation, and then, be maintained in sediments for a lengthy period (23). Therefore, sediments are the basic tanks of PAHs in the aquatic environments, so that in suitable environmental conditions, precipitated PAHs can enter the water and lead to bioaccumulation in the food chain (24-26).

Bushehr province with a shoreline more than $707 \mathrm{~km}$ is located along the Persian Gulf in Iran southwestern. This province due to its strategic situation is one of the most momentous harbors in Iran and a major place 
for petroleum transportation. Because of the high compression of oil conveniences and significant increase of petroleum contamination risk, this region has become one of the damaged areas in the world. However, there is few information about PAH contaminations in all harbors of Bushehr province $(27,28)$. The aim of this study was to present comparative and complete information about the PAHs pollution status in the sediments, feasible sources of PAHs and ecotoxicological effects of PAHs in 5 harbors (Asaluyeh, Kangan, Khark, Emam Hasan, and Bushehr) of Bushehr province.

\section{Materials and Methods Sampling}

A total number of 300 sediment samples (15 samples from each station) (at depth of $0-5 \mathrm{~cm}$ ) were collected from 20 sites of Persian Gulf costs (Bushehr province, Iran), by a clean stainless-steel spatula, in Assaluyeh, Kangan, Khark, Emam Hasan, and Bushehr coastal areas during January and February 2019 using GPS (Figure 1). The samples were placed into aluminum jar and stored on ice and transmitted immediately to the laboratory.
In the laboratory, sediments were freeze-dried for 24 $\mathrm{h}$, homogenized, transferred into a glass jar washed by $\mathrm{n}$-hexane and covered in foil, and kept at $-20^{\circ} \mathrm{C}$ until the test.

\section{Analysis of PAHs}

Standards of PAHs including benzo (g.h.i) perylene (BP), dibenz [a,h]anthracene (DA), pyrene (IP), benzo[a] pyrene $(\mathrm{BaP})$, indeno $(1,2,3, \mathrm{~cd})$, benzo(b)fluoranthene $(\mathrm{BbF})$, benzo(k)fluoranthene $(\mathrm{BkF})$, Chrysene $(\mathrm{CH})$, Pyrene (PY), fluoranthene (FLU), Anthracene (AN), phenanthrene $(\mathrm{PH})$, fluorene $(\mathrm{FL})$, acenaphthene (ACE), acenaphthylene (ACY), naphthalene (NA), benzo(a) anthracene $(\mathrm{BaA}), \mathrm{n}$-hexane, and dichloromethane, were purchased from Merck (Germany).

In order to analyze the PAHs, dried sediments (10 g) were mixed with $250 \mathrm{~mL}$ of $\mathrm{n}$-hexane:dichloromethane at a volume ratio of $1: 1$, and the mixture was placed in Soxhlet for 8 hours. The combined extract was condensed on a rotary vacuum evaporator for $15 \mathrm{~mL}$. Activated copper was added to remove sulfur and its compounds, then, the residual was passed through a filter paper
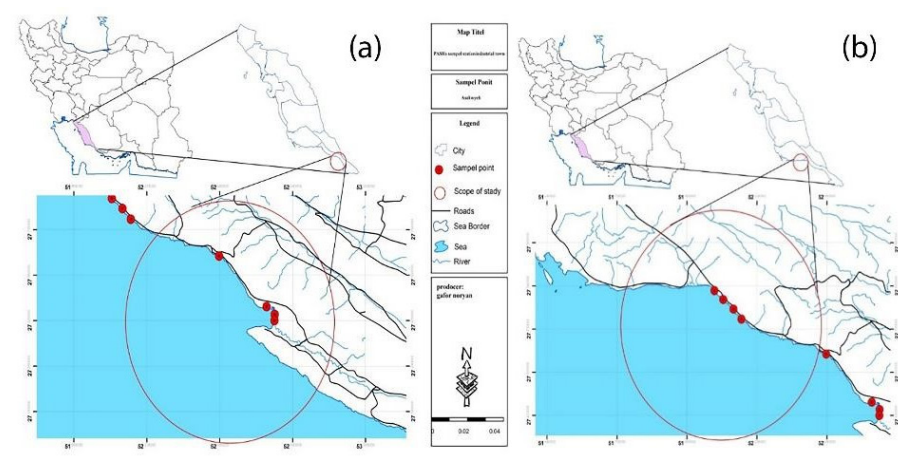

(b)
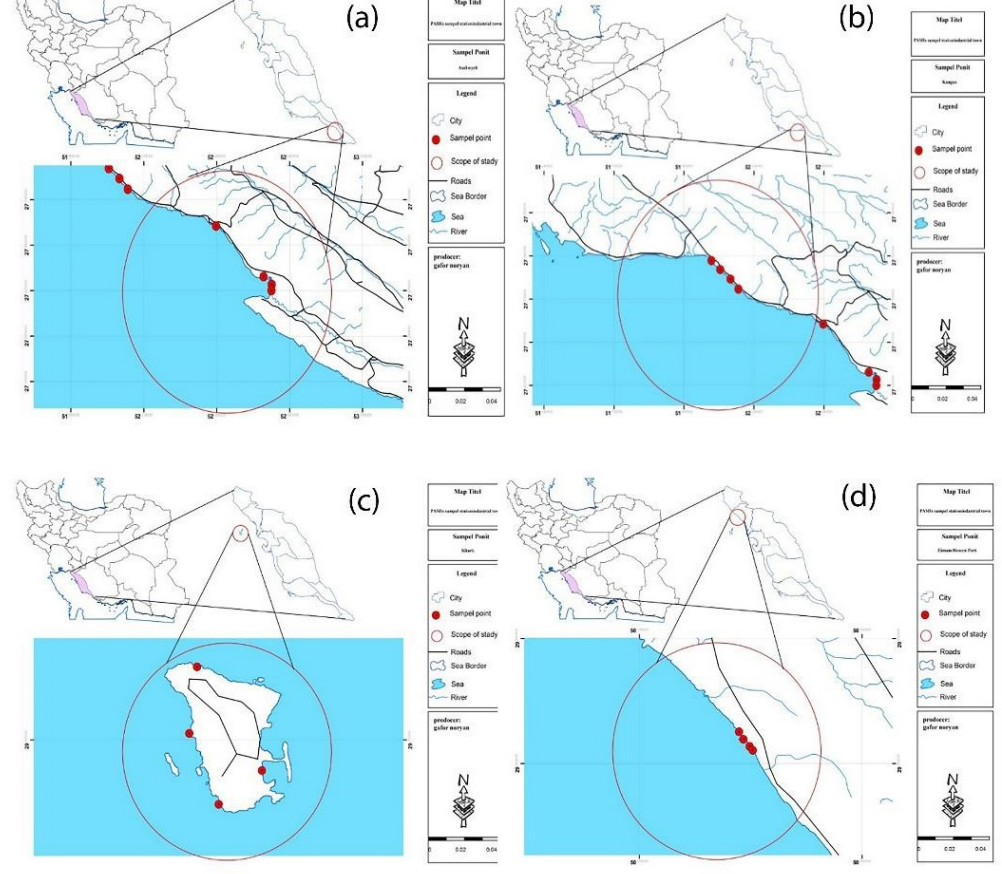

(d)
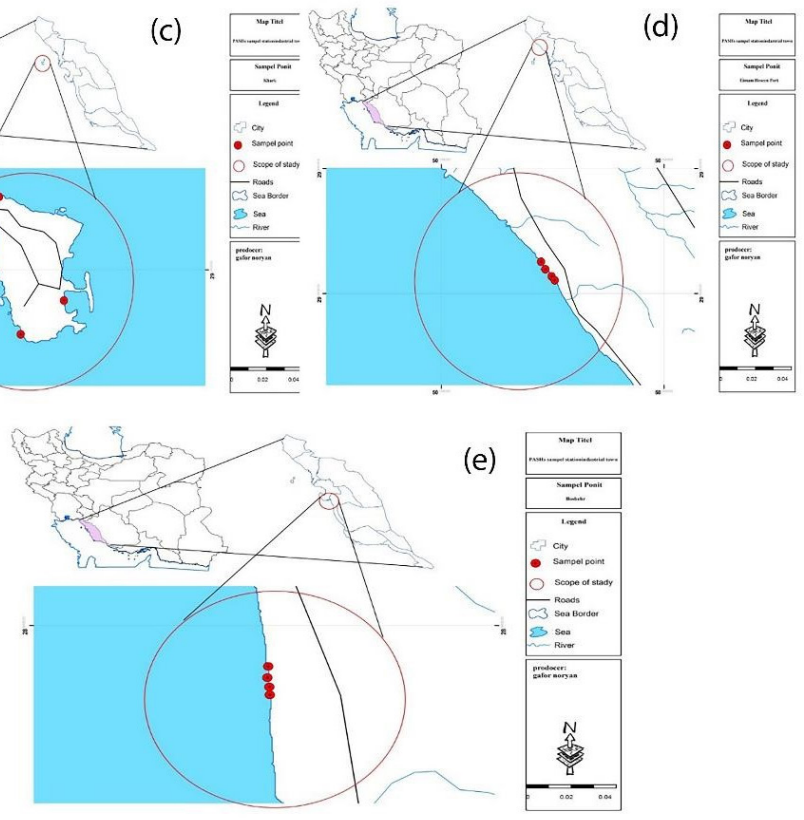

Figure 1. Plot of the study areas and sampling stations in the (a) Assaluyeh, (b) Kangan, (c) Khark, (d) Emam Hasan, and (e) Bushehr stations. 
(Whatman GF/C, 24 microns) for 24 hours. The extract passed through a column including alumina (10 g), sodium anhydrous sulfate $(2 \mathrm{~g})$, and silica (10 g). The mixture of dichloromethane and $n$-hexane $(30 \mathrm{~mL})$ was added to the column at a volume ratio of 1:9. The content of the sample was regulated again at $5 \mathrm{~mL}$. The extract was dried with a nitrogen gas stream, and then, $1 \mathrm{~mL}$ of acetonitrile was added to it (29).

The HPLC device (Younglin 9100) was employed to analyze the PAHs in the samples. HPLC was equipped with a fluorescence (Agilent 1100) and UV detector (youngling 9120). The column type of the reverse phase was $C_{18}(250$ $\times 4.5 \mathrm{~mm}, 5 \mu \mathrm{m})$. The initial mobile phase was HPLC grade water (60\%) and acetonitrile (40\%), which changed to $100 \%$ acetonitrile in $20 \mathrm{~min}$ and held at $100 \%$ for 7 minutes, then, reduced to the primary phase. Peak area of external standards (PAH mix, CRM47940, Supelco) and decachlorobiphenyl as internal standard (48318, Supelco) were used to obtain internal standard calibration curves and to measure the PAHs.

To obtain the recovery values of the method, a hexanewashed sediment was heated at $250^{\circ} \mathrm{C}$ for 12 hours and polluted with PAH mix solution at 500 ppb level. Then, the obtained sediment was treated as other samples. The recovery values ranged from $71 \%$ to $86 \%$ for all PAHs.

\section{Source identification}

The correlation ratios among the values of the single PAHs indicating that they all originated from one similar origin or not (30). Moreover, different sources of PAHs in sediments can be expected depending on PAHs composition. Low molecular weight (LMW, 2-3-ring) PAHs are produced by a petrogenic source, whereas high molecular weight (HMW, 4-6-ring) PAHs have a pyrogenic source. Therefore, $\Sigma$ LPAHs/ $\Sigma$ HPAHs $<1$ shows pyrogenic sources and $\Sigma$ LPAHs/ $\Sigma$ HPAHs $>1$ refers to petrogenic sources (31). In this study, $\mathrm{PAH}$ isomers including $\mathrm{PH} /$ $\mathrm{AN}$ and $\mathrm{AN} /(\mathrm{PH}+\mathrm{AN})$ ratios were also used to evaluate possible sources of PAHs. $\mathrm{PH} / \mathrm{AN}$ and $\mathrm{AN} /(\mathrm{PH}+\mathrm{AN})$ ratios higher than 10 and lower than 0.1 indicate pollution of petroleum products, and ratios lower than 10 and higher than 0.1 show pyrogenic activities $(3,22)$. The ratio of $\mathrm{IP} /(\mathrm{IP}+\mathrm{BP})$ is also an important indicator of the PAHs sources assessment in sediments, which was also studied in this research. When the ratio of IP/(IP + BP) is lower than 0.2 , it is originated from petrogenic sources and if it is between 0.2 and 0.5 , demonstrates liquid fuel combustion, and a ratio more than 0.5 is related to combustion processes of solid fuel (32).

\section{Ecological risk assessment}

Sediment toxicity was calculated with the toxic equivalent factor (TEF). The toxicity evaluation of sediments was performed according to the values of total carcinogenic PAHs (cPAHs) including DA, BaP, IP, BkF, CH, BbF, and $\mathrm{BaA} . \mathrm{BaP}$ (the most toxic combination of PAHs) was considered as the reference $\mathrm{PAH}$, to which the TEF value of 1 was dedicated, whereas other combinations of PAHs had lower TEF values compared with the BaP. According to the United States Environmental Protection Agency (USEPA), the TEFs values for DA, BaP, IP, BkF, $\mathrm{CH}, \mathrm{BbF}$, and $\mathrm{BaA}$ were $1,1,0.1,0.01,0.001,0.1$, and 0.1 , respectively. The TEQ in each station was estimated by the following equation $(33,34)$ :

$\mathrm{TEQ}=\Sigma\left(\mathrm{TEF}_{\mathrm{i}}{ }^{*} \mathrm{CPAH}_{\mathrm{i}}\right)$

Where $T E F_{i}$ is toxic equivalent factor for any $\mathrm{cPAH}$ and $\mathrm{CPAH}_{i}$ is carcinogenic PAH values ( $\mathrm{ng} / \mathrm{g} \mathrm{dw}$ ).

Sediment quality guidelines (SQGs) and sediment quality criteria (SQC) have been used to measure the PAHs ecotoxicological effects in sediments. The SQGs standard contains two effect levels: Effect range low (ERL) and effect range median (ERM). If PAHs amounts are less than ERL, it means that the toxicity possibility and other effects are rare. If concentrations are equivalent or higher than the ERL and less than ERM, negative biological effects may be happening sporadically. Values equivalent to or higher than the ERM mean that a negative biological efficacy would happen frequently (35). The SQCs standard includes five effect levels including rare effect level (REL), threshold effect level (TEL), occasional effect level (OEL), probable effect level (PEL), and frequent effect level (FEL) (36).

Another method for assessing the possible ecotoxicological effect of single chemicals is calculating the mean ERM quotient (M-ERM-Q) for all PAHs. M-ERM-Q was calculated using Eq. (2):

$\mathrm{M}-\mathrm{ERM}-\mathrm{Q}=\frac{\Sigma(c i / E R M i)}{n}$

Where $C i$ is the amount of any PAHi, ERMi is ERM of any PAHi, and $n$ is the number of PAHs.

The M-ERM-Q lower than 0.1, 0.11-0.51, 0.51-1.5, and more than 1.5 have $\leq 11 \%$ (low pollution), $25-30 \%$ (medium to low pollution), 46-53\% (medium to high pollution), and $\geq 75 \%$ (high pollution) probability of toxicity, respectively (15).

\section{Analysis of data}

The data were analyzed using SPSS version 23 for Windows. The results were presented as the mean \pm standard deviation. Statistical significant level was considered at $P<0.05$. The following data were analyzed: (a) the values of each PAH; (b) 16 PAHs concentration; (c) the total carcinogenic PAHs (DA, BaP, IP, BkF, CH, BbF, and BaA).

Results

Analysis of PAHs

The PAHs concentrations in sediment samples of 20 
stations are shown in Table 1. The $\Sigma$ PAHs ranged from ND (all stations in Bushehr( to $49180 \mathrm{ng} / \mathrm{g} \mathrm{dw}$ (4 stations in Asaluyeh) with a medium value of $6894.55 \pm 14301.55$ ng/g dw.

Figure 2 shows the composition profiles of PAHs in the sediments. Generally, PAHs compounds with 2 and 3 rings were dominant in the Asaloyeh, Kangan, Khark, and Emam Hasan sediments and included 71.85\%, 56.12\%, $71.15 \%$, and $76.79 \%$ of $\Sigma$ PAHs, respectively.

\section{Source identification}

In order to study the source of PAHs, the Pearson's correlation ratios of individual PAHs in 20 sediment samples of Bushehr province are illustrated in Table 2. Significant positive correlations were observed for several PAHs pairs: ACE-ACY, FL-ACY, FL-ACE, AN-ACY, ANACE, AN-FL, FLU-NA, FLU-PH, PY-ACY, PY-ACE, PYFL, PY-AN, BkF-PH, BkF-FLU, BaP-NA, BaP-PH, BaPBkF, IP-ACY, IP-ACE, IP-FL, IP-AN, IP-PY, DA-ACY, DA-ACE, DA-FL, DA-AN, DA-PY, and DA-IP. BaA, CH, $\mathrm{BbF}$, and $\mathrm{BP}$ show no significant correlation with the other PAHs studied.

The other parameter used to identify the origins of PHAs is $\Sigma$ LPAHs/ $\Sigma$ HPAHs ratio. According to Figure 2, $\Sigma$ LPAHs/ $\Sigma$ HPAHs ratio at stations $\mathrm{A}_{1}, \mathrm{~K}_{1}, \mathrm{~K}_{3}, \mathrm{Kh}_{1}$, and $\mathrm{B}_{2}$ was less than 1 and this ratio at other stations was higher than 1.

Figure 3 shows the values of $\mathrm{PH} / \mathrm{AN}, \mathrm{AN} /(\mathrm{PH}+\mathrm{AN})$, and $\mathrm{IP} /(\mathrm{IP}+\mathrm{BP}) . \mathrm{PH} / \mathrm{AN}$ and $\mathrm{AN} /(\mathrm{PH}+\mathrm{AN})$ in all sites were lower than $10 . \mathrm{IP} /(\mathrm{IP}+\mathrm{BP})$ in all sites were higher than 0.5 .

\section{Ecological risk assessment}

According to Figure 2, PAHs compounds with 2 and 3 rings, which are LMW, are dominant in the Asaloyeh, Kangan, Khark, and Emam Hasan sediments. LMW PAHs (e.g., NA and FL) are toxic and non-carcinogenic for aquatic organisms; while several HMW PAHs (e.g., BaP and $\mathrm{BbF}$ ) are mutagenic and carcinogenic to organisms like fish, birds, and mammals (37).

In this study, the toxicity of sediments was estimated

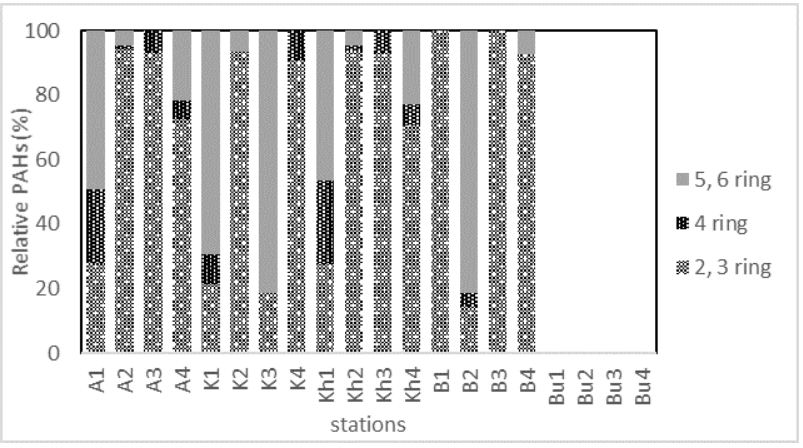

Figure 2. Percentage PAHs composition based on benzene ring in the sediment samples.

based on the total quantity of the seven carcinogenic PAHs including $\mathrm{CH}, \mathrm{BbF}, \mathrm{BaA}, \mathrm{BaP}, \mathrm{BkF}$, IP, and DA. As indicated in Table 1, the medium values of $\Sigma \mathrm{CPAHs}$ in sediment samples of 20 stations ranged from ND to 10690 $\mathrm{ng} / \mathrm{g}$, with a medium amount of $1629.37 \pm 3541.39 \mathrm{ng} / \mathrm{g}$ dw. In addition, $\Sigma$ CPAHs were $0 \%$ to $86 \%$ of $\Sigma$ PAHs.

In this research, the total TEQ car levels of sediments ranged from ND to $7999 \mathrm{ngTEQ} / \mathrm{g} \mathrm{dw}$, with a medium amount of $804.77 \pm 2338.80 \mathrm{ngTEQ} / \mathrm{g}$ dw. In addition, the mean of TEQ car values in the Asaluyeh, Kangan, Khark, Emam Hasan, and Bushehr stations were 1884.29, 36.32, 2069.02, 34.25, and ND ng TEQ/g dw, respectively (Table 1). In addition, higher amounts for total TEQ were reported compared to those reported by Qiao et al (38); on the other hand, Sprovieri et al (39) reported lower amounts.

The m-ERM-q amounts of PAHs in 20 stations are shown in Table 1. These values varied from ND to 7.414 with a mean value of $1.197 \pm 2.42$.

The comparative evaluation of the values of ERL and ERM (SQGs) for PAHs are presented in Table 3. In this study, the $\Sigma \mathrm{PAH}$ concentration in $60 \%$ of all sites was lower than ERL (rare negative effects), but $30 \%$ of all sites had a $\Sigma$ PAHs concentration higher than ERL and lower than ERM (sporadically negative effects) and $\Sigma$ PAHs concentration in $10 \%$ of all samples (related to Asalouyeh and Khark stations) were higher than the ERM (frequently

Table 1. Comparison of $\Sigma \mathrm{PAHs}$ (ng/g) in sediments of studied stations with other locations

\begin{tabular}{|c|c|c|c|}
\hline Location & ¿PAHs & Contamination Level & References \\
\hline Bushehr Province shores & ND - 49180 & Low to very high & Present study \\
\hline Daya Bay, China & $42.5-158.2$ & Low & $(45)$ \\
\hline Khark Island, SW Iran & $2.95-253.3$ & Low to moderate & $(47)$ \\
\hline Norwegian Harbor, Norway & $2000-76000$ & High to very high & $(42)$ \\
\hline Commercial ports from Spain & $260-66,710$ & Moderate to very high & $(41)$ \\
\hline Intertidal zone, Yangtze Estuary, China & $263-6372$ & Moderate to very high & $(48)$ \\
\hline Boston Harbor, USA & $7300-358000$ & Very high & $(43)$ \\
\hline Kaohsiung Harbor, Taiwan & $472-16207$ & Moderate to very high & $(24)$ \\
\hline Pearl River Delta, China & $52.7-717$ & Low to moderate & $(44)$ \\
\hline Intertidal zone, Bohai Bay, Northeast China & $37.2-206.6$ & Low to moderate & $(49)$ \\
\hline
\end{tabular}




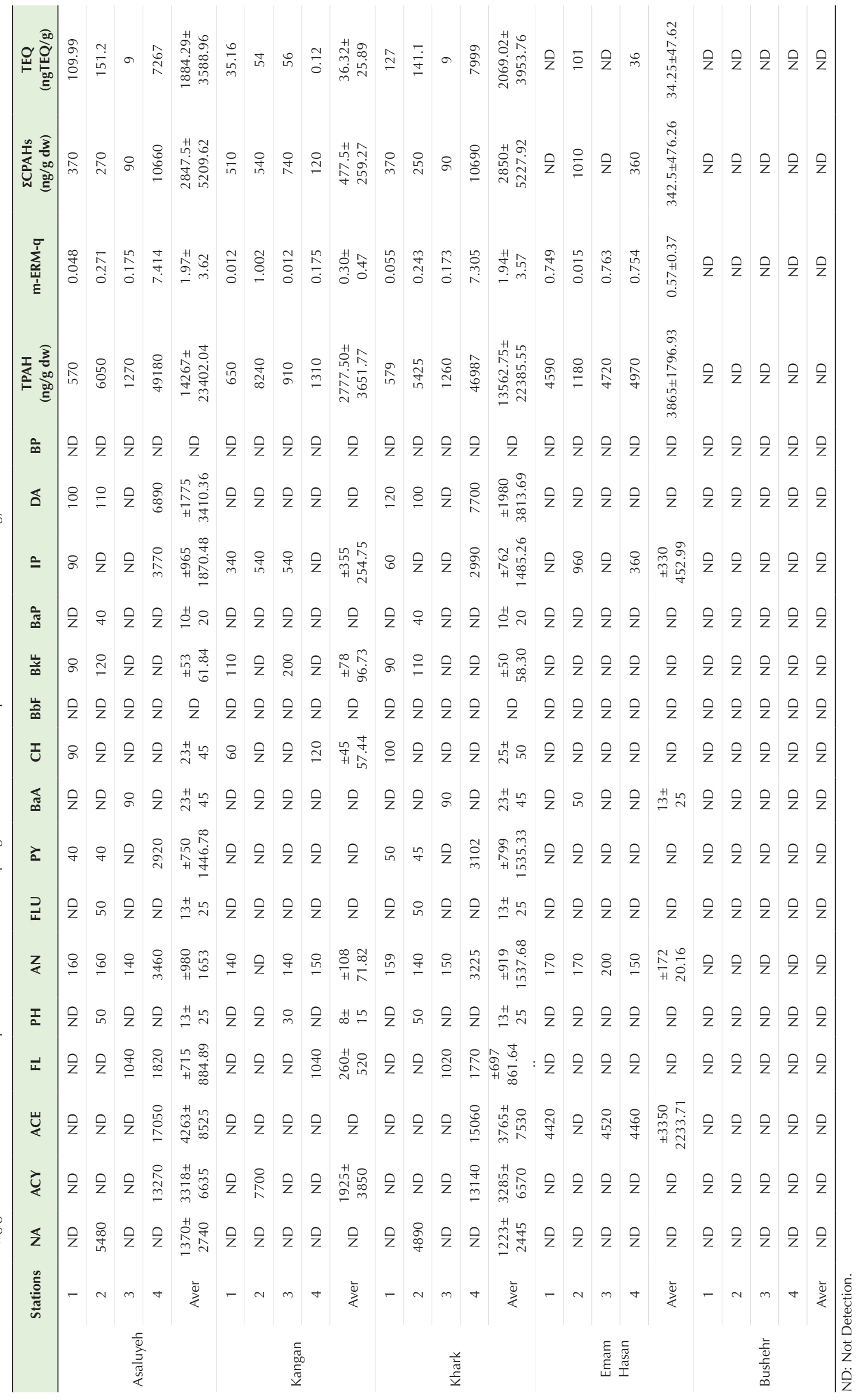



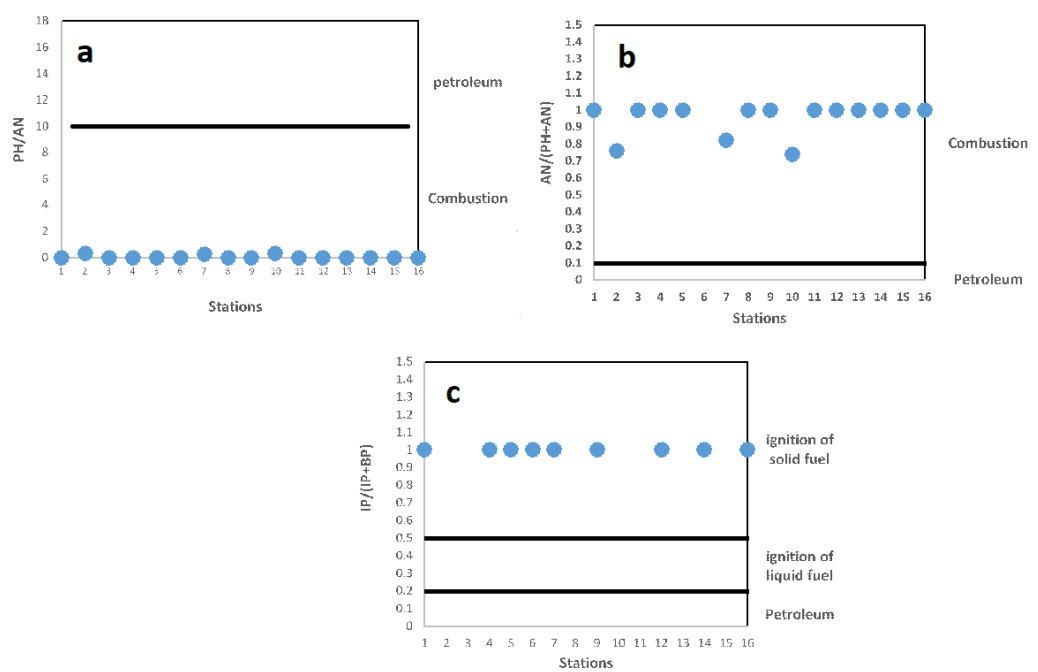

Figure 3. Plan of isomeric ratios of a) $\mathrm{PH} / \mathrm{AN}$, b) $\mathrm{AN} / \mathrm{PHAN}$, and c) IP/(IP+BP).

negative effects). In relation to the individual compounds, ERL values exceeded for AN and DA in $81.25 \%$ and $25 \%$ of all samples, respectively; but the ERM values exceeded for NA, AN, PY, and DA in $12.5 \%$, for ACY in $18.75 \%$, and for ACE and FL in $31.25 \%$ of all samples.

The findings presented in Figure 4 show that the amounts of 12 PAHs at $77.5 \%$ of the sites were lower than their corresponding REL values, and PAHs concentrations at $6 \%$ of all stations (including Asaluyeh and Khark stations) also exceeded FEL levels.
Discussion

\section{Analysis of PAHs}

According to Table 1 and based on the one-way ANOVA, the difference in the $\Sigma$ PAHs between sediment samples in Bushehr province was not significant $(P>0.05)$. The higher PAHs concentrations in sediments of Asaluyeh and Khark areas compared to other areas can be because of the discharge of sewage from gas and oil refineries, municipal sewage, oil leakages into the aquatic environments. The lower amounts of PAHs in Bushehr province stations may be related to stations far from harbors and municipal

Table 3. Pearson's correlation coefficient for PAH concentrations in sediments in Bushehr province

\begin{tabular}{|c|c|c|c|c|c|c|c|c|c|c|c|c|c|c|c|c|}
\hline \multirow{2}{*}{ PAHs } & \multicolumn{16}{|c|}{ PAHs } \\
\hline & NA & $\mathrm{ACY}$ & ACE & FL & PH & AN & FLU & PY & $\mathrm{BaA}$ & $\mathrm{CH}$ & $\mathrm{BbF}$ & BkF & $\mathrm{BaP}$ & IP & DA & BP \\
\hline NA & 1 & & & & & & & & & & & & & & & \\
\hline $\mathrm{ACY}$ & -0.136 & 1 & & & & & & & & & & & & & & \\
\hline ACE & -0.156 & $0.851^{* *}$ & 1 & & & & & & & & & & & & & \\
\hline $\mathrm{FL}$ & 0.08 & $0.707^{* *}$ & $0.717^{* *}$ & 1 & & & & & & & & & & & & \\
\hline $\mathrm{PH}$ & 0.417 & -0.167 & -0.191 & -0.225 & 1 & & & & & & & & & & & \\
\hline AN & -0.096 & $0.903^{* *}$ & $0.952^{* *}$ & $0.807^{* *}$ & -0.121 & 1 & & & & & & & & & & \\
\hline FLU & $0.475^{*}$ & -0.136 & -0.156 & -0.183 & $0.912^{* *}$ & -0.098 & 1 & & & & & & & & & \\
\hline PY & -0.107 & $0.915^{* *}$ & $0.939^{* *}$ & $0.796^{* *}$ & -0.126 & $0.995^{* *}$ & -0.090 & 1 & & & & & & & & \\
\hline $\mathrm{BaA}$ & 0.363 & -0.166 & -0.190 & 0.314 & -0.166 & -0.119 & -0.135 & -0.140 & 1 & & & & & & & \\
\hline $\mathrm{CH}$ & -0.161 & -0.197 & -0.226 & 0.002 & -0.198 & -0.141 & -0.161 & -0.154 & -0.196 & 1 & & & & & & \\
\hline $\mathrm{BbF}$ & $0^{\mathrm{a}}$ & $0^{\mathrm{a}}$ & $0^{\mathrm{a}}$ & $0^{\mathrm{a}}$ & $0^{\mathrm{a}}$ & $0^{\mathrm{a}}$ & $0^{\mathrm{a}}$ & $0^{\mathrm{a}}$ & $0^{\mathrm{a}}$ & $0^{\mathrm{a}}$ & $0^{\mathrm{a}}$ & & & & & \\
\hline BkF & 0.155 & -0.250 & -0.287 & -0.337 & $0.687^{* *}$ & -0.181 & $0.449^{*}$ & -0.194 & -0.249 & 0.231 & $0^{\mathrm{a}}$ & 1 & & & & \\
\hline $\mathrm{BaP}$ & $0.475^{*}$ & -0.136 & -0.156 & -0.183 & $0.912^{* *}$ & -0.098 & 1.00 & -.099 & -0.135 & -0.161 & $0^{\mathrm{a}}$ & $0.449^{*}$ & 1 & & & \\
\hline IP & -0160 & $0.915^{* *}$ & $0.908^{* *}$ & $0.728^{* *}$ & -0.145 & $0.963^{* *}$ & -0.160 & $0.954^{* *}$ & -0.10 & -0.187 & $0^{\mathrm{a}}$ & -0.160 & -0.160 & 1 & & \\
\hline DA & -0.105 & $0.913^{* *}$ & $0.937^{* *}$ & $0.795^{* *}$ & -0.125 & $0.993^{* *}$ & -0.099 & $1.000^{* *}$ & -0.139 & -0.154 & $0^{\mathrm{a}}$ & -0.194 & -0.099 & $0.949^{* *}$ & 1 & \\
\hline BP & $0^{\mathrm{a}}$ & $0^{\mathrm{a}}$ & $0^{\mathrm{a}}$ & $0^{\mathrm{a}}$ & $0^{\mathrm{a}}$ & $0^{\mathrm{a}}$ & $0^{\mathrm{a}}$ & $0^{\mathrm{a}}$ & $0^{\mathrm{a}}$ & $0^{\mathrm{a}}$ & $0^{\mathrm{a}}$ & $0^{\mathrm{a}}$ & $0^{\mathrm{a}}$ & $0^{\mathrm{a}}$ & $0^{\mathrm{a}}$ & $0^{\mathrm{a}}$ \\
\hline
\end{tabular}

"Relationship is significant at the 0.05 level.

"Relationship is significant at the 0.01 level (2-tailed).

${ }^{a}$ Cannot be calculated because at least one of the variables is constant. 


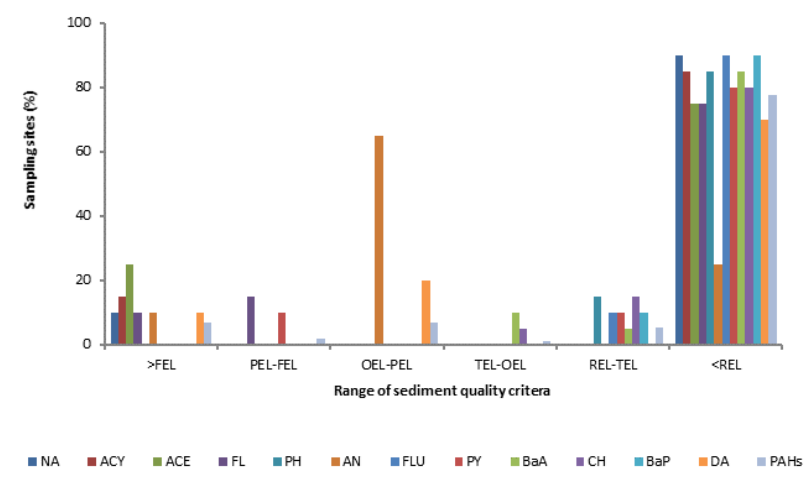

Figure 4. PAHs risk evaluation based on the sediment quality criteria in Canada.

regions and the lack of direct evacuations.

PAHs is classified into four groups including low (0-100 $\mathrm{ng} / \mathrm{g})$, medium (100-1000 ng/g), high (1000-5000 ng/g), and very high (>5000 ng/g) pollution (40). Accordingly, sediments from Bushehr province shores can be classified as low to very highly contaminated by PAHs.

The PAHs contamination levels at sediment samples of Bushehr province shores are consistent with the results reported by Chen and Chen (24) and Casado-Martínez et al (41) but are less than those reported in the Norwegian harbor in Norway (42) and Boston port in the USA (43). However, higher levels of PAHs contamination in sediment samples were reported compared to those reported by Wang et al (44) and Yan et al (45) (Table 4). The differences in values of PAHs at different areas sediments around the world may be due to the differences in PAHs compounds, geological features of sampling stations and source of contamination. In addition, tides can also be effective in the distribution of PAHs.

\section{Source identification}

According to Table 2, individual PAHs that have significant positive correlations, may be originated from common anthropogenic sources, but can be originated from another source except for local anthropological sources for individual PAHs with no significant positive association.

The main PAHs sources at coastal sediments include combustion processes (pyrogenic sources) and petroleum products (petrogenic sources) (46). In the studied area, the origin of PAHs at stations $A_{1}, K_{1}, K_{3}, K h_{1}$, and $B_{2}$ is pyrogenic and the origin of PAHs at the rest of the stations is petrogenic as $\Sigma$ LPAHs/ $\Sigma$ HPAHs ratios at stations $\mathrm{A}_{1}$, $\mathrm{K}_{1}, \mathrm{~K}_{3}, \mathrm{Kh}_{1}$, and $\mathrm{B}_{2}$ were less than 1 while the ratios were reported to be higher than 1 at other stations (Figure 2).

As shown in Figure 3, the values of PH/AN in all sites were lower than 10, indicating that pyrogenic sources played a major role in sediment pollution. In this study, the results of the ratios of $\mathrm{AN} /(\mathrm{PH}+\mathrm{AN})$ were similar to the results of $\mathrm{PH} / \mathrm{AN}$ ratios. Accordingly, the IP/(IP + BP) in all sites were more than 0.5 , indicating that pyrogenic sources are dominant (Figure 3).

In conclusion, the three ratios of $\mathrm{AN} /(\mathrm{AN}+\mathrm{PH})$, FLU/ $(\mathrm{FLU}+\mathrm{PY})$, and $\mathrm{CH} /(\mathrm{BaA}+\mathrm{CH})$ present similar findings. Pyrogenic PAHs were predominant in the studied area samples, which can be caused by diesel engine output. Furthermore, traffic and coal burning can increase the PAHs values through rainfalls and runoff. Based on the $\Sigma$ LPAHs/ $\Sigma$ HPAHs ratio, in some areas, petrogenic sources may help PAHs pollutions, which could originate from oil/diesel/gas leakages and oily effluent discharge.

\section{Ecological risk assessment}

The m-ERM-q amounts of PAHs in Table 1 show that Bushehr stations are categorized as a low group $(\leq 11 \%$ probability of toxicity), Kangan stations as a medium-low group (25\%-30\% probability of toxicity), Emam Hasan station as medium-high group (46\%-53\% probability of toxicity), and Asaluyeh and Khark stations as high priority groups ( $\geq 75 \%$ probability of toxicity).

According to the values of ERL and ERM (SQGs) for PAHs presented in Table 5, it was revealed that some sites perhaps have single PAHs that sporadically and frequently cause negative ecotoxicological risk effects.

The SQCs are based on SQGs according to technical, natural, social, economic conditions and etc. In the present study, PAHs pollution levels were evaluated based on the standard SQC values in Canada (Table 5) (36). These values can be employed in the management of environmental such as recovery, dragging, and contamination control.

The findings show that the amounts of 12 PAHs at $77.5 \%$ of the sites were lower than their corresponding

Table 4. The percentage of ERL and ERM (SQGs) for PAHs in the sediment samples

\begin{tabular}{|c|c|c|c|c|}
\hline \multirow{2}{*}{ PAHs } & \multirow{2}{*}{$\begin{array}{l}\text { (ng/g dw) SQGs: } \\
\text { ERL-ERM }\end{array}$} & \multicolumn{3}{|c|}{ SQGs } \\
\hline & & $<$ ERL $(\%)$ & ERL-ERM (\%) & $>\operatorname{ERM}(\%)$ \\
\hline NA & $160-2100$ & 90 & - & 10 \\
\hline $\mathrm{ACY}$ & $44-640$ & 85 & - & 15 \\
\hline ACE & $16-500$ & 75 & - & 25 \\
\hline $\mathrm{FL}$ & $19-540$ & 75 & - & 25 \\
\hline $\mathrm{PH}$ & 240-1500 & 100 & - & - \\
\hline AN & $85.3-1100$ & 25 & 65 & 10 \\
\hline FLU & $600-5100$ & 100 & - & - \\
\hline PY & $660-2600$ & 90 & - & 10 \\
\hline $\mathrm{BaA}$ & 261-1600 & 100 & - & - \\
\hline $\mathrm{CH}$ & $384-2800$ & 100 & - & - \\
\hline $\mathrm{BbF}$ & - & - & - & - \\
\hline BbK & - & - & - & - \\
\hline $\mathrm{BaP}$ & 430-1600 & 100 & - & - \\
\hline IP & - & - & - & - \\
\hline DA & $63.4-260$ & 70 & 20 & 10 \\
\hline BP & - & - & - & - \\
\hline $\mathrm{PAHs} \Sigma$ & $4022-44792$ & 60 & 30 & 10 \\
\hline
\end{tabular}


Table 5. Evaluation criteria of coastal sediment quality for PAHs in Canada (ng/g)

\begin{tabular}{lccccc}
\hline PAH & REL & TEL & OEL & PEL & FEL \\
\hline NA & 17 & 35 & 120 & 390 & 1200 \\
\hline ACY & 3.3 & 5.9 & 31 & 130 & 340 \\
\hline ACE & 3.7 & 6.7 & 21 & 89 & 940 \\
\hline FL & 10 & 21 & 61 & 140 & 1200 \\
\hline $\mathrm{PH}$ & 23 & 87 & 250 & 540 & 2100 \\
\hline $\mathrm{AN}$ & 16 & 47 & 110 & 240 & 1100 \\
\hline $\mathrm{FLU}$ & 27 & 110 & 500 & 1500 & 4200 \\
\hline $\mathrm{PY}$ & 41 & 150 & 420 & 1400 & 3800 \\
\hline $\mathrm{BaA}$ & 27 & 75 & 280 & 690 & 1900 \\
\hline $\mathrm{CH}$ & 37 & 110 & 300 & 850 & 2200 \\
\hline $\mathrm{BbF}$ & - & - & - & - & - \\
\hline $\mathrm{BbK}$ & - & - & - & - & - \\
\hline $\mathrm{BaP}$ & 34 & 89 & 230 & 760 & 1700 \\
\hline $\mathrm{IP}$ & - & - & - & - & - \\
\hline $\mathrm{DA}$ & 3.3 & 6.2 & 43 & 140 & 200 \\
\hline $\mathrm{BP}$ & - & - & - & - & - \\
\hline & & & & &
\end{tabular}

REL values, indicating that harmful PAHs effects in these areas are rare (Figure 4). PAHs concentrations at $6 \%$ of all stations (including Asaluyeh and Khark stations) also exceeded FEL levels, indicating that negative effects of PAH compounds in these areas occur frequently (Figure 4). So now, further evaluation on the environmental risks of PAHs compounds in these areas is required because there is low surface sediment that needs to be corrected.

\section{Conclusion}

In this study, considerable information on the distribution, probable origin, and ecotoxicology efficacy of PAHs in the surface sediments from Bushehr Province shores are presented. The levels of PAHs in sediments from sampling sites are low to very high. In stations of $\mathrm{A} 1, \mathrm{~K} 1, \mathrm{~K} 3, \mathrm{Kh} 1$, and B2, 4-6-ring PAHs were abundant in sediments, whereas, $\Sigma$ LPAHs/ $\Sigma$ HPAHs ratios at other stations were higher than 1. Based on the three PAHs isomeric ratios, the pollutants of sediments were originated from combustion processes (pyrogenic sources). In relation to the ecotoxicological assessment, $\Sigma$ PAHs concentration and several single PAHs in some sites exceeded ERM, indicating frequent negative effects of ecotoxicological risk. The findings of biological effect evaluation showed that coastal sediments of Bushehr province shores have 11\% (Bushehr stations) to 75\% (Asaluyeh and Khark stations) probability of toxicity. The SQC also indicated that the possibility of negative effects of 12 PAHs composition is low. Nevertheless, toxic effects related to NA, ACY, ACE, FL, AN, and DA would occur frequently in Asaluyeh and Khark stations. Therefore, station sediments must be routinely sampled for PAHs because PAHs may have a negative effect on the marine ecosystems, organisms, and humans.

Acknowledgements

Authors would like to express their gratitude to Bushehr Islamic Azad University for supporting this research.

Ethical issues

Not applicable.

Competing interests

The authors declare that they have no conflict of interests.

Author's contributions

GN performed experiments and drafted the manuscript. NJ, TT, $\mathrm{EK}$, and ARP reviewed the manuscript. All authors contributed to the critical reading and discussion of the manuscript. All authors have read and approved the published version of the manuscript.

\section{References}

1. Ncube S, Madikizela L, Cukrowska E, Chimuka L. Recent advances in the adsorbents for isolation of polycyclic aromatic hydrocarbons (PAHs) from environmental sample solutions. Trends Analyt Chem 2018; 99: 101-16. doi: 10.1016/j.trac.2017.12.007.

2. Meng Y, Liu X, Lu S, Zhang T, Jin B, Wang Q, et al. A review on occurrence and risk of polycyclic aromatic hydrocarbons (PAHs) in lakes of China. Sci Total Environ 2019; 651(Pt 2): 2497-506. doi: 10.1016/j.scitotenv.2018.10.162.

3. Raeisi A, Arfaeinia H, Seifi M, Shirzad-Siboni M, Keshtkar M, Dobaradaran S. Polycyclic aromatic hydrocarbons (PAHs) in coastal sediments from urban and industrial areas of Asaluyeh Harbor, Iran: distribution, potential source and ecological risk assessment. Water Sci Technol 2016; 74(4): 957-73. doi: 10.2166/wst.2016.265.

4. Amouei A, Fallah H, Asgharnia H, Mousapour A, Parsian $\mathrm{H}$, Hajiahmadi $\mathrm{M}$, et al. Comparison of heavy metals contamination and ecological risk between soils enriched with compost and chemical fertilizers in the North of Iran and ecological risk assessment. Environ Eng Manag J 2020; 7(1): 7-14. doi: 10.34172/EHEM.2020.02.

5. Baghaie AH, Aghili F. Investigation of heavy metals concentration in soil around a PbZn mine and ecological risk assessment. Environ Eng Manag J 2019; 6(3): 151-6. doi: 10.15171/EHEM.2019.17.

6. Yadegarnia Naeini F, Azimzadeh H, Mosleh Arani A, Sotoudeh A, Kiani B. Ecological risk assessment of heavy metals from cement factory dust. Environ Eng Manag J 2019; 6(2): 129-37. doi: 10.15171/EHEM.2019.15.

7. Baghaie AH, Daliri A. The effect of organic chelates and gibberellic acid on petroleum hydrocarbons degradation in the soil co-contaminated with $\mathrm{Ni}$ and crude oil under canola cultivation. Environ Eng Manag J 2020; 7(1): 15-22. doi: 10.34172/EHEM.2020.03.

8. Keshavarzifard M, Moore F, Keshavarzi B, Sharifi R. Distribution, source apportionment and health risk assessment of polycyclic aromatic hydrocarbons (PAHs) in intertidal sediment of Asaluyeh, Persian Gulf. Environ Geochem Health 2018; 40(2): 721-35. doi: 10.1007/s10653017-0019-2. 
9. Janadeleh H, Kameli MA, Boazar C. Seasonal variations of metal pollution and distribution, sources, and ecological risk of polycyclic aromatic hydrocarbons (PAHs) in sediment of the Al Hawizah wetland, Iran. Hum Ecol Risk Assess 2018; 24(4): 886-903. doi: 10.1080/10807039.2016.1277416.

10. Abdel-Shafy HI, Mansour MS. A review on polycyclic aromatic hydrocarbons: source, environmental impact, effect on human health and remediation. Egypt J Petrol 2016; 25(1): 107-23. doi: 10.1016/j.ejpe.2015.03.011.

11. Rivera-Pérez A, Romero-González R, Garrido Frenich A. Persistent organic pollutants (PCBs and $\mathrm{PCDD} /$ Fs), PAHs, and plasticizers in spices, herbs, and tea-A review of chromatographic methods from the last decade (2010-2020). Crit Rev Food Sci Nutr 2021; 1-21. doi: 10.1080/10408398.2021.1883546.

12. Singh L, Varshney JG, Agarwal T. Polycyclic aromatic hydrocarbons' formation and occurrence in processed food. Food Chemistry 2016; 199: 768-81. doi: 10.1016/j. foodchem.2015.12.074.

13. Anyahara JN. Effects of Polycyclic Aromatic Hydrocarbons (PAHs) on the environment: a systematic review. International Journal of Advanced Academic Research 2021; 7(3): 12-26. doi: 10.46654/ij.24889849.e7303.

14. Lee DW, Lee H, Lee AH, Kwon BO, Khim JS, Yim UH, et al. Microbial community composition and PAHs removal potential of indigenous bacteria in oil contaminated sediment of Taean coast, Korea. Environ Pollut 2018; 234: 503-12. doi: 10.1016/j.envpol.2017.11.097.

15. dos Santos IF, Ferreira SL, Domínguez C, Bayona JM. Analytical strategies for determining the sources and ecotoxicological risk of PAHs in river sediment. Microchemical Journal 2018; 137: 90-7. doi: 10.1016/j. microc.2017.09.025.

16. Montuori P, Aurino S, Garzonio F, Sarnacchiaro P, Nardone A, Triassi M. Distribution, sources and ecological risk assessment of polycyclic aromatic hydrocarbons in water and sediments from Tiber River and estuary, Italy. Sci Total Environ 2016; 566-7: 1254-67. doi: 10.1016/j. scitotenv.2016.05.183.

17. Qiao X, Zheng B, Li X, Zhao X, Dionysiou DD, Liu $Y$. Influencing factors and health risk assessment of polycyclic aromatic hydrocarbons in groundwater in China. J Hazard Mater 2021; 402: 123419. doi: 10.1016/j. jhazmat.2020.123419.

18. Wang Z, Liu Z, Xu K, Mayer LM, Zhang Z, Kolker AS, et al. Concentrations and sources of polycyclic aromatic hydrocarbons in surface coastal sediments of the northern Gulf of Mexico. Geochem Trans 2014; 15(1): 2. doi: 10.1186/1467-4866-15-2.

19. Tuvikene A. Responses of fish to polycyclic aromatic hydrocarbons (PAHs). Annales Zoologici Fennici 1995; 32(3): 295-309.

20. Rocha MJ, Rocha E. Concentrations, sources and risks of PAHs in dissolved and suspended material particulate fractions from the Northwest Atlantic Coast of the Iberian Peninsula. Mar Pollut Bull 2021; 165: 112143. doi: 10.1016/j. marpolbul.2021.112143.

21. Zeng Q, Jeppesen E, Gu X, Mao Z, Chen H. Distribution, fate and risk assessment of PAHs in water and sediments from an aquaculture-and shipping-impacted subtropical lake, China. Chemosphere 2018; 201: 612-20. doi: 10.1016/j. chemosphere.2018.03.031.

22. Giacalone A, Gianguzza A, Mannino MR, Orecchio S, Piazzese D. Polycyclic aromatic hydrocarbons in sediments of marine coastal lagoons in Messina, Italy: extraction and GC/MS analysis, distribution and sources. Polycyclic Aromatic Compounds 2004; 24(2): 135-49. doi: 10.1080/10406630490433223.

23. Tu YT, Ou JH, Tsang DC, Dong CD, Chen CW, Kao CM. Source identification and ecological impact evaluation of PAHs in urban river sediments: A case study in Taiwan. Chemosphere 2018; 194: 666-74. doi: 10.1016/j. chemosphere.2017.12.008.

24. Chen CW, Chen CF. Distribution, origin, and potential toxicological significance of polycyclic aromatic hydrocarbons (PAHs) in sediments of Kaohsiung Harbor, Taiwan. Mar Pollut Bull 2011; 63(5-12): 417-23. doi: 10.1016/j.marpolbul.2011.04.047.

25. Ge M, Wang X, Yang G, Wang Z, Li Z, Zhang X, et al. Persistent organic pollutants (POPs) in deep-sea sediments of the tropical western Pacific Ocean. Chemosphere 2021; 277: 130267. doi: 10.1016/j.chemosphere.2021.130267.

26. Han B, Li Q, Liu A, Gong J, Zheng L. Polycyclic aromatic hydrocarbon (PAH) distribution in surface sediments from Yazhou Bay of Sanya, South China, and their source and risk assessment. Mar Pollut Bull 2021; 162: 111800. doi: 10.1016/j.marpolbul.2020.111800.

27. Mahmoodi M, Safahieh A, Nikpour Y, Ghanemi K. Distribution and sources of polycyclic aromatic hydrocarbons in the sediment of Bushehr coastal zoneIran. Iranica Journal of Energy \& Environment 2012; 3(2): 173-9. doi: 10.5829/idosi.ijee.2012.03.02.0311.

28. Dashtbozorg M, Bakhtiari AR, Shushizadeh MR, Taghavi L. Quantitative evaluation of n-alkanes, PAHs, and petroleum biomarker accumulation in beach-stranded tar balls and coastal surface sediments in the Bushehr Province, Persian Gulf (Iran). Mar Pollut Bull 2019; 146: 801-15. doi: 10.1016/j.marpolbul.2019.07.023.

29. Moopam A. Manual of oceanographic observation and pollution analysis. regional or-ganization for the protection of Marine Environment (ROPME Publishing);1999.

30. Soclo H, Garrigues P, Ewald M. Origin of polycyclic aromatic hydrocarbons (PAHs) in coastal marine sediments: case studies in Cotonou (Benin) and Aquitaine (France) areas. Mar Pollut Bull 2000; 40(5): 387-96. doi: 10.1016/S0025326X(99)00200-3.

31. Keshavarzifard M, Moore F, Keshavarzi B, Sharifi R. Polycyclic aromatic hydrocarbons (PAHs) in sediment and sea urchin (Echinometra mathaei) from the intertidal ecosystem of the northern Persian Gulf: Distribution, sources, and bioavailability. Mar Pollut Bull 2017; 123(1-2): 373-80. doi: 10.1016/j.marpolbul.2017.09.008.

32. Duodu GO, Ogogo KN, Mummullage S, Harden F, Goonetilleke A, Ayoko GA. Source apportionment and risk assessment of PAHs in Brisbane River sediment, Australia. Ecological Indicators 2017; 73: 784-99. doi: 10.1016/j. ecolind.2016.10.038.

33. Rastegari Mehr M, Keshavarzi B, Moore F, Sacchi E, Lahijanzadeh AR, Eydivand $S$, et al. Contamination level and human health hazard assessment of heavy 
metals and polycyclic aromatic hydrocarbons (PAHs) in street dust deposited in Mahshahr, southwest of Iran. Hum Ecol Risk Assess 2016; 22(8): 1726-48. doi: 10.1080/10807039.2016.1219221.

34. Chen F, Lin Y, Cai M, Zhang J, Zhang Y, Kuang W, et al. Occurrence and risk assessment of PAHs in surface sediments from Western Arctic and Subarctic Oceans. Int J Environ Res Public Health 2018; 15(4): 734. doi: 10.3390/ ijerph15040734.

35. Birch GF. A review of chemical-based sediment quality assessment methodologies for the marine environment. Mar Pollut Bull 2018; 133: 218-32. doi: 10.1016/j. marpolbul.2018.05.039.

36. He X, Pang Y, Song X, Chen B, Feng Z, Ma Y. Distribution, sources and ecological risk assessment of PAHs in surface sediments from Guan River Estuary, China. Mar Pollut Bull 2014; 80(1-2): 52-8. doi: 10.1016/j.marpolbul.2014.01.051.

37. Edokpayi JN, Odiyo JO, Popoola OE, Msagati TA. Determination and distribution of polycyclic aromatic hydrocarbons in rivers, sediments and wastewater effluents in Vhembe District, South Africa. Int J Environ Res Public Health 2016; 13(4): 387. doi: 10.3390/ijerph13040387.

38. Qiao M, Wang C, Huang S, Wang D, Wang Z. Composition, sources, and potential toxicological significance of PAHs in the surface sediments of the Meiliang Bay, Taihu Lake, China. Environ Int 2006; 32(1): 28-33. doi: 10.1016/j. envint.2005.04.005.

39. Sprovieri M, Feo ML, Prevedello L, Manta DS, Sammartino S, Tamburrino S, et al. Heavy metals, polycyclic aromatic hydrocarbons and polychlorinated biphenyls in surface sediments of the Naples harbour (southern Italy). Chemosphere 2007; 67(5): 998-1009. doi: 10.1016/j. chemosphere.2006.10.055.

40. Baumard P, Budzinski H, Michon Q, Garrigues P, Burgeot $\mathrm{T}$, Bellocq J. Origin and bioavailability of PAHs in the Mediterranean Sea from mussel and sediment records. Estuar Coast Shelf Sci 1998; 47(1): 77-90. doi: 10.1006/ ecss.1998.0337.

41. Casado-Martínez MC, Buceta JL, Belzunce MJ, Delvalls TA. Using sediment quality guidelines for dredged material management in commercial ports from Spain. Environ Int
2006; 32(3): 388-96. doi: 10.1016/j.envint.2005.09.003.

42. Oen AM, Cornelissen G, Breedveld GD. Relation between $\mathrm{PAH}$ and black carbon contents in size fractions of Norwegian harbor sediments. Environmental Pollution 2006; 141(2): 370-80. doi: 10.1016/j.envpol.2005.08.033.

43. Wang XC, Zhang YX, Chen RF. Distribution and partitioning of polycyclic aromatic hydrocarbons (PAHs) in different size fractions in sediments from Boston Harbor, United States. Mar Pollut Bull 2001; 42(11): 1139-49. doi: 10.1016/s0025-326x(01)00129-1.

44. Wang HS, Cheng Z, Liang P, Shao DD, Kang Y, Wu SC, et al. Characterization of PAHs in surface sediments of aquaculture farms around the Pearl River Delta. Ecotoxicol Environ Saf 2010; 73(5): 900-6. doi: 10.1016/j. ecoenv.2010.04.010.

45. Yan W, Chi J, Wang Z, Huang W, Zhang G. Spatial and temporal distribution of polycyclic aromatic hydrocarbons (PAHs) in sediments from Daya Bay, South China. Environmental Pollution. Environmental Pollution 2009; 157(6): 1823-30. doi: 10.1016/j.envpol.2009.01.023.

46. Boonyatumanond R, Wattayakorn G, Togo A, Takada H. Distribution and origins of polycyclic aromatic hydrocarbons (PAHs) in riverine, estuarine, and marine sediments in Thailand. Mar Pollut Bull 2006; 52(8): 942-56. doi: 10.1016/j.marpolbul.2005.12.015.

47. Akhbarizadeh R, Moore F, Keshavarzi B, Moeinpour A. Aliphatic and polycyclic aromatic hydrocarbons risk assessment in coastal water and sediments of Khark Island, SW Iran. Mar Pollut Bull 2016; 108(1-2): 33-45. doi: 10.1016/j.marpolbul.2016.05.004.

48. Liu M, Hou LJ, Yang Y, Zou H, Lu J, Wang X. Distribution and sources of polycyclic aromatic hydrocarbons in intertidal flat surface sediments from the Yangtze estuary, China. Environmental Geology 2001; 41(1-2): 90-5. doi: $10.1007 / \mathrm{s} 002540100347$.

49. Qian X, Liang B, Fu W, Liu X, Cui B. Polycyclic aromatic hydrocarbons (PAHs) in surface sediments from the intertidal zone of Bohai Bay, Northeast China: Spatial distribution, composition, sources and ecological risk assessment. Mar Pollut Bull 2016; 112(1-2): 349-58. doi: 10.1016/j.marpolbul.2016.07.040. 